This article was downloaded by: [Virginia Polytechnic Institute \& State University]

On: 14 March 2009

Access details: Access Details: [subscription number 906466435]

Publisher Taylor \& Francis

Informa Ltd Registered in England and Wales Registered Number: 1072954 Registered office: Mortimer House, 37-41 Mortimer Street, London W1T 3JH, UK

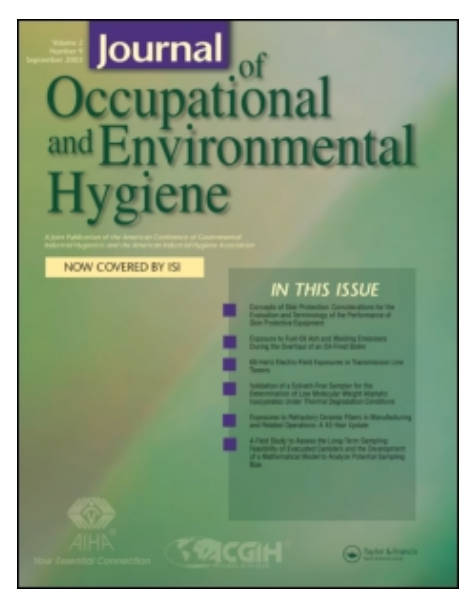

Journal of Occupational and Environmental Hygiene

Publication details, including instructions for authors and subscription information:

http://www.informaworld.com/smpp/title content=t713657996

\title{
Dust Control Technology Usage Patterns in the Drywall Finishing Industry
}

Deborah E. Young-Corbett a; Maury A. Nussbaum ${ }^{b}$

${ }^{a}$ Department of Civil and Environmental Engineering, Myers-Lawson School of Construction, Virginia Tech, Blacksburg, Virginia ${ }^{b}$ Department of Industrial and Systems Engineering, Virginia Tech, Blacksburg, Virginia

First Published on: 01 June 2009

To cite this Article Young-Corbett, Deborah E. and Nussbaum, Maury A.(2009)'Dust Control Technology Usage Patterns in the Drywall Finishing Industry',Journal of Occupational and Environmental Hygiene,6:6,315 - 323

To link to this Article: DOI: $10.1080 / 15459620902836815$

URL: http://dx.doi.org/10.1080/15459620902836815

\section{PLEASE SCROLL DOWN FOR ARTICLE}

\footnotetext{
Full terms and conditions of use: http://www.informaworld.com/terms-and-conditions-of-access.pdf

This article may be used for research, teaching and private study purposes. Any substantial or systematic reproduction, re-distribution, re-selling, loan or sub-licensing, systematic supply or distribution in any form to anyone is expressly forbidden.

The publisher does not give any warranty express or implied or make any representation that the contents will be complete or accurate or up to date. The accuracy of any instructions, formulae and drug doses should be independently verified with primary sources. The publisher shall not be liable for any loss, actions, claims, proceedings, demand or costs or damages whatsoever or howsoever caused arising directly or indirectly in connection with or arising out of the use of this material.
} 


\title{
Dust Control Technology Usage Patterns in the Drywall Finishing Industry
}

\author{
Deborah E. Young-Corbett ${ }^{1}$ and Maury A. Nussbaum ${ }^{2}$ \\ ${ }^{1}$ Department of Civil and Environmental Engineering, Myers-Lawson School of Construction, \\ Virginia Tech, Blacksburg, Virginia \\ ${ }^{2}$ Department of Industrial and Systems Engineering, Virginia Tech, Blacksburg, Virginia
}

A telephone survey was conducted to quantify drywall finishing industry usage rates of dust control technology, identify barriers to technology adoption, and explore firm owner perception of risk. Industry use of the following technologies was described: wet methods, respiratory protection, pole sanders, ventilated sanders, and low-dust joint compound. A survey instrument composed of both Likert-type scaled items and open-ended items was developed and administered by telephone to the census population of the owners of member firms of trade associations: Finishing Contractors Association and Association of the Wall and Ceiling Industries. Of 857 firms, 264 interviews were completed. Along with descriptive statistics, results were analyzed to examine effects of firm size and union affiliation on responses. Responses to open-ended items were analyzed using content analysis procedures. Firm owners rated the risk of dust to productivity and customer satisfaction as low-moderate. Half rated the dust as having some impact on worker health, with higher impacts indicated by owners of small firms. Among the available control technologies, respiratory protection was used most frequently. Several barriers to implementation of the more effective control technologies were identified. Barriers associated with technology usability, productivity, and cost, as well as misperceptions of risk, should be addressed to improve dust control in the drywall finishing industry.

Keywords construction work, drywall, dust, dust control, perception of risk

Address correspondence to: Deborah E. Young-Corbett, Civil and Environmental Engineering, Myers-Lawson School of Construction, 310B Bishop Favrao Hall, Blacksburg, VA 24061; e-mail: dyoung@vt.edu.

\section{INTRODUCTION}

$\mathrm{W}$ orkers in the plastering and wall finishing trades suffer from disproportionately high rates of respiratory disease and disability. Several recent epidemiologic studies have found associations between drywall finishing work and the morbidity and mortality of respiratory disease. In a study of proportionate mortality patterns for male construction workers in North Carolina, Wang et al. ${ }^{(1)}$ found a significant cancer risk for painters, plasterers, paperhangers, and drywall workers. This group had significantly elevated proportionate mortality ratios (PMRs) for malignant neoplasm of the pharynx (PMR $=178)$, trachea and bronchus $(\mathrm{PMR}=118)$, and of pneumoconiosis/other respiratory disease $(\mathrm{PMR}=152)$. Specifically, drywall finishers and laborers had a statistically elevated risk of death from cancer of the pharynx $(\mathrm{PMR}=133)$ and lung $(\mathrm{PMR}=110)$, and respiratory tuberculosis $(\mathrm{PMR}=675) . \mathrm{In}$ an epidemiologic study specific to the plastering trade, PMRs and proportionate cancer mortality ratios (PCMRs) were calculated using U.S. death rate information for all 99 causes of death listed for the 12,873 members of the Operative Plasterers' and Cement Masons' International Association who died between 1972 and $1996 .^{(2)}$ Members of the plasterer subgroup of this trade union perform a variety of tasks, including interior and exterior plastering of drywall, cement, stucco, and stone imitation; preparation, installation, and repair of all insulation systems; and the fireproofing of steel beams and columns. Some of the potential occupational health hazards to which this group was exposed included calcite, gypsum, mica, talc, silica, fiberglass, and asbestos. Among plasterers, significantly elevated mortality was observed for lung cancer and for benign neoplasm.

While the association between occupational exposure to mineral dust and the etiology of diseases of the lung has been well established, more recent attention has been directed at possible connections between construction work and disease of the upper airways. In a retrospective cohort study ${ }^{(3)}$ in Finland, construction work involving high exposures to mineral dusts was associated with an elevated risk of asthma. These authors suggested that irritant mineral dusts are the etiologic agents in the reactive airway symptoms and recommended further investigation to identify specific agents. Arif et al. ${ }^{(4)}$ found an association between asthma and construction work in a review of the data from the Third National Health and Nutrition Examination Survey 1988-1994. Kaukianen et al. ${ }^{(5)}$ found that construction painters experience a high prevalence of symptoms of upper-airway disease and that this prevalence was significantly 
higher than that of other construction-related trades workers. In a study of how asthma symptoms impact worker ability to perform construction work, ${ }^{(6)}$ construction workers had a higher rate of job change due to work conditions compared with a control group. In addition, construction worker quality of work life was greatly diminished by the exacerbation of asthma symptoms caused by the working conditions. The main asthma-inducing work conditions identified were the presence of dust, cold air, and physical exertion. Drywall dust was implicated as an agent of concern.

Drywall finishing operations have been associated with worker over-exposure to dust that contains known particulate respiratory health hazards, such as silica, talc, and mica. ${ }^{(7)}$ There is evidence that the dust generated from drywall finishing operations exceeds published occupational exposure limits for those dust constituents that have published limits, and that there are additional unregulated constituents that are suspected of having negative impacts on respiratory health. ${ }^{(7)}$ In the most exhaustive industrial hygiene assessment of construction worker chemical exposures, Verma et al. ${ }^{(8)}$ found that airborne particulate matter was the most prevalent hazard class. In this study of 1265 task-based assessments, the authors found that dust affects not only the workers involved in direct exposurecausing tasks but also those performing ancillary activities. Construction tasks evaluated included framing, bricklaying, excavating, foundation building, interior carpentry, insulating, dry walling, painting, and plumbing. The tasks associated with the highest dust generation were drywall and concrete operations.

A study of exposure to silica dust in the U.S. construction industry found that "silica exposures are grossly unacceptable in the U.S. construction industry."(9) Personal sampling was performed for workers in the following trades: bricklayers, wall finishers, and laborers. Probabilities of overexposure were estimated to be between $64.5 \%$ and $100 \%$ for silica and between $8.2 \%$ and $89.2 \%$ for other dust. The authors indicated that engineering and administrative controls are needed to reduce worker exposures. Silica exposures significantly reduced by wet methods of dust suppression (300\% reduction in concentrations) and ventilated enclosures (600\% reduction in exposure concentration). The authors concluded that urgent action is needed to address silica overexposure in the construction industry.

The National Institute for Occupational Safety and Health (NIOSH) conducted an evaluation of worker exposure to drywall dust and potential health effects associated with drywall finishing work during renovation activities. ${ }^{(7)}$ In this study of 10 workers performing drywall-sanding tasks, the main constituents of drywall joint compound, worker respiratory symptoms, and dust exposure levels were evaluated. Bulk samples of drywall joint compound were analyzed and constituents were identified as calcite, quartz (silica), talc, mica, gypsum, clays (attapulgite and kaolinite), and perlite. Calcite, a form of calcium carbonate $\left(\mathrm{CaCO}_{3}\right)$, was the primary constituent of all samples. Workers were overexposed to total dust, respirable fraction dust, and crystalline silica. Concentrations were compared with the Occupational Safety and Health Administration (OSHA) permissible exposure limits (PEL) of $15 \mathrm{mg} / \mathrm{m}^{3}$ for total dust and $5 \mathrm{mg} / \mathrm{m}^{3}$ for the respirable fraction. Nearly all ( 8 of 9) total dust samples exceeded the PEL and 2 of 13 exceeded the respirable PEL. Respirable silica (quartz) was detected in 17 of the 22 samples analyzed.

The NIOSH study ${ }^{(7)}$ also found that respiratory symptoms were common among drywall finishers and tended to improve when workers were away from the workplace. Phlegm production, morning or day cough, and shortness of breath were the most common symptoms. Irritated eyes and stuffy nose were reported by smaller percentages of the workers; however, all who reported these symptoms also reported their resolution when away from the work setting. These upper respiratory symptoms are consistent with those associated with excessive calcite exposure among chalk powder manufacturing workers. ${ }^{(10)}$ This latter study also indicated significant acrossshift declines in all parameters associated with airway obstruction and that calcite exposure levels correlated with airway function decrements.

Methods currently available to control drywall dust include ventilated sanding, wet sanding, pole sanding, respiratory protection, and a recently marketed low-dust joint compound. Ventilated sanding technology involves a vacuum system with a collection hood near the sanding surface. Dust is collected at the point of generation and pulled into a collection basin. Wet sanding is accomplished using two different methods. In one method, the drywall compound is allowed to cure and then rewetted. Rewetting is accomplished either by misting or wiping a damp sponge or cloth over the surface. A second method involves a single tool that is a combination of a sponge and a sanding screen. In pole sanding, the sanding surface is attached to one end of a pole and the worker holds the other end while performing the operation. This reduces worker exposure to the dust by removing the worker from the point of dust generation. While sanding poles were originally designed for the purpose of reaching distant surfaces, NIOSH recognized that they have some value in preventing worker dust exposure. ${ }^{(11)}$ Low-dust joint compound, which was patented by the $3 \mathrm{M}$ Company in 1998, contains a dust-reducing additive, such as an oil, surfactant, wax, or petroleum derivative, that purportedly reduces the amount of dust resulting from sanding hardened joint compound. This compound entered the marketplace in October 2006.

Despite the existence of engineering and work practice control technologies for the mitigation of the dust hazard, worker exposures persist in the construction industry. Respiratory protection is not the preferred method of controlling worker exposure to inhalation hazards because it places an additional burden on the worker and requires medical clearance, fitting, and training. For these reasons, engineering or work practice controls are preferred.

A NIOSH hazard control study found that vacuum sanding systems reduce drywall dust levels by $80 \%$ to $97 \% .^{(11)}$ 
Also, pole sanding systems reduced worker exposure levels by removing the sanding task from the worker breathing zone. Work practice controls, such as wet sanding, were effective in reducing dust levels. Respiratory protective devices if fitted and worn properly did reduce worker exposure to dust by up to $99.99 \%$. In terms of reducing dust in the thoracic and respirable size classes, the ventilated sander appears superior to wet methods and pole sanders, and wet and pole methods superior to ordinary block sanding. ${ }^{(12)}$

There are important gaps in the existing knowledge base regarding this occupational health problem. A clear picture of industry usage trends for the various available technologies is needed. The NIOSH National Occupational Research Agenda (NORA) National Construction Agenda has a stated goal to "Use existing information supplemented by survey research to develop a baseline on current silica control practices and programs in construction." (13,p.42) Furthermore, information about drywall firm owners' and managers' perceptions of the risks associated with the dust and barriers to adoption of dust control measures is needed to develop interventions to improve usage rates. The objective of the current study was to quantify industry usage rates of the commercially available dust control technologies (vacuum sanders, wet methods, respiratory protection, pole sanders, and low-dust joint compound). Also evaluated were firm owner perceptions of risks associated with drywall dust and potential barriers to the use of controls.

\section{METHODS}

\section{Sampling Design}

The study population consisted of the owners of member firms of two professional trade organizations: the Finishing Contractors Association (FCA) and the Association of the Wall and Ceiling Industries (AWCI). The FCA is the international trade association of U.S. and Canadian contractors in the drywall finishing, glass and glazing, floor covering, painting and decorating, and signs and display trades. All FCA members are signatory to collective bargaining agreements with the International Union of Painters and Allied Trades (IUPAT). AWCI represents contracting firms for acoustics systems, ceiling systems, drywall systems, exterior insulation and finishing systems, fireproofing, flooring systems, insulation, and stucco contractors, and those in allied trades. As of April 2007, the FCA had 1400 contractor members, including 342 drywall finishing firms, and the AWCI had 515 drywall finishing firm members. According to the U.S. Census Bureau, there were 19,828 drywall finishing firms and 293,781 workers employed by these firms in 2004 . $^{(14)}$

\section{Survey Instrument Design}

A survey instrument was designed to gather information about dust control practices and dust control technologies used in the drywall industry. Survey items regarding the risk of negative impacts of drywall dust on productivity, customer
TABLE I. Risk Perception Descriptive Statistics

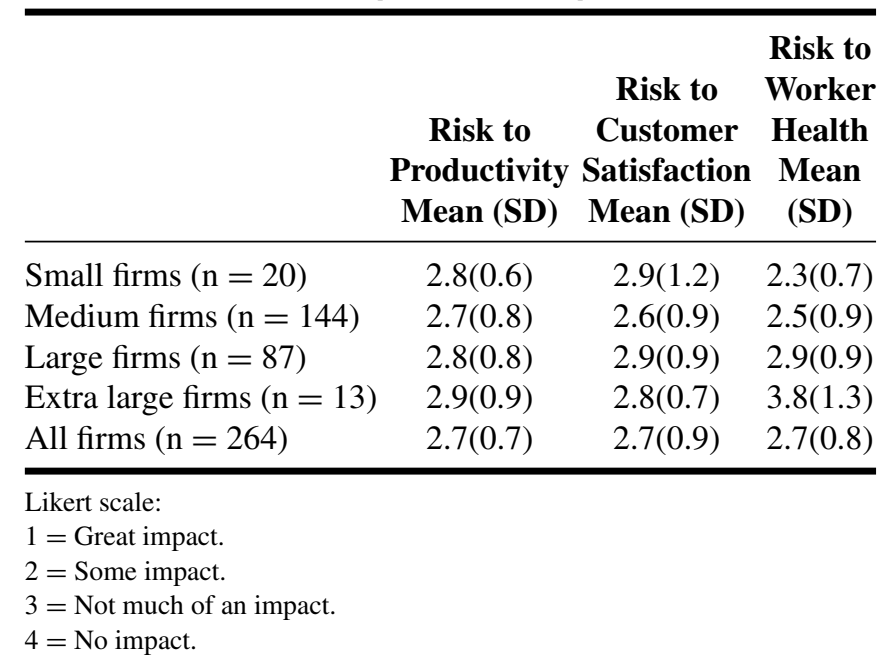

satisfaction, and human health were included. Responses were made using a 4-point Likert-type scale (Table I). The instrument also contained items about use of wet methods, respiratory protection, pole sanders, ventilated/vacuum sanders, and low-dust joint compound. These responses were made on a 5-point Likert-type scale (Table II). Respondents answering "rarely" or "never" on these items were subsequently asked "why not?" Survey respondents were also asked to list any additional methods for controlling dust employed by their firms and to share any additional information about their experience with dust and dust control. Responses to openended questions were transcribed verbatim. A final set of questions addressed key demographic information of interest: number of employees and union affiliation.

\section{Data Collection Procedures}

Telephone interview protocols were reviewed and approved by the Institutional Review Board of Virginia Tech. All telephone calls were made in April 2007, in a standardized manner, using a computer assisted telephone interviewing software system (Sawtooth Technologies' WinCATI 4.2). Each interviewer collecting data for the survey participated in a prior project-specific training session. Interviews began with a brief summary of project objectives, a review of informed consent information, and an assurance that firm identity would never be linked to responses and that only aggregate data would be published.

Interviews were conducted with either firm owners or managers. All calls were monitored by a phone bank supervisor to ensure data accuracy and adherence to proper interviewing protocol. Each of the 857 drywall finishing firms was contacted until reached or to a maximum of nine attempts. These attempts were made at different times of day and on different days of the week. Firms reporting no drywall finishing work were excluded from the survey $(\mathrm{N}=217)$. Nonworking telephone numbers, out of service/disconnected numbers, and answering 
TABLE II. Dust Control Technology Use Descriptive Statistics

\begin{tabular}{|c|c|c|c|c|c|}
\hline & $\begin{array}{c}\text { Use of } \\
\text { Wet } \\
\text { Methods }\end{array}$ & $\begin{array}{c}\text { Use of } \\
\text { Respiratory } \\
\text { Protection }\end{array}$ & $\begin{array}{c}\text { Use of } \\
\text { Pole } \\
\text { Sanders }\end{array}$ & $\begin{array}{c}\text { Use of } \\
\text { Ventilated } \\
\text { Sanders }\end{array}$ & $\begin{array}{c}\text { Use of } \\
\text { Low-Dust } \\
\text { Mud }\end{array}$ \\
\hline Union firms $(\mathrm{n}=166)$ & $3.7(1.0)$ & $1.2(0.7)$ & $1.9(1.0)$ & $2.9(1.4)$ & $3.6(1.5)$ \\
\hline Non-union firms $(\mathrm{n}=98)$ & $3.6(1.1)$ & $1.5(1.1)$ & $2.0(1.3)$ & $2.8(1.2)$ & $3.6(1.4)$ \\
\hline Small firms $(\mathrm{n}=20)$ & $4.0(0.9)$ & $1.5(0.4)$ & $1.2(0.8)$ & $3.3(1.4)$ & $3.4(1.6)$ \\
\hline Medium firms $(n=144)$ & $3.5(1.1)$ & $1.3(0.8)$ & $1.9(1.1)$ & $2.8(1.3)$ & $3.5(1.4)$ \\
\hline Large firms $(\mathrm{n}=87)$ & $3.8(1.1)$ & $1.4(1.0)$ & $2.1(1.3)$ & $2.9(1.3)$ & $3.8(1.5)$ \\
\hline Extra large firms $(\mathrm{n}=13)$ & $3.8(1.0)$ & $1.4(0.6)$ & $1.6(0.8)$ & $3.1(0.9)$ & $3.3(1.1)$ \\
\hline All firms $(n=264)$ & $3.7(1.1)$ & $1.3(0.8)$ & $1.9(1.2)$ & $2.9(1.3)$ & $3.6(1.4)$ \\
\hline
\end{tabular}

Likert scale:

$1=$ Always.

$2=$ Often

$3=$ Sometimes.

$4=$ Rarely.

$5=$ Never.

services were excluded $(\mathrm{N}=109)$. The remaining pool of eligible firms was 531, with a total of 264 interviews completed, representing a response rate of $50 \%$. Responding firms employed a total of 25,782 workers.

\section{Analysis}

In addition to descriptive summaries of the scaled survey items, a preliminary multivariate analysis of variance (MANOVA) was used to determine effects of firm size and union status on the set of dependent variables as a whole. Firm size was categorized into four size classes: small (110), medium (11-100), large (101-1,000), and very large (1001-10,000). Results indicated a significant effect of firm size $(F(1,262)=7.46, p=0.007)$ but no effect of union status or the interaction. Subsequently, analysis of variance (ANOVA) was run to determine the effect of firm size on each dependent measure individually. Where relevant, post hoc paired comparisons were performed using Tukey's HSD. All statistical analyses were performed using JMP 6.0.2 (SAS Institute Inc., Cary, N.C.), with significance determined when $p<0.05$.

Responses to open-ended survey items were analyzed using content analysis procedures. Codes that were both exhaustive and mutually exclusive were established for each set of openended responses by the first author. Eight sets of codes emerged from the analysis. These codes were then assigned to responses by two independent coders with education in conducting human factors research and who had been trained (by the first author) on the particular coding definitions and process. Intercoder reliability was calculated for each set of codes, using Krippendorff's alpha, with an acceptance criterion of $\alpha \geq$ $0.8{ }^{(15)}$ Across all sets of codes, $\alpha$ was greater than 0.86 ; hence, all were retained.

\section{RESULTS}

\section{Descriptive Statistics \\ Perception of Risk}

Means and standard deviations for responses to the three risk perception questions are summarized in Table I, and percentages of firm owner responses are depicted in Figure 1. Of the three types of potential risks evaluated, the highest perceived likelihood was associated with risk to worker health (Figure 1). Slightly more than half the firm owners reported a perceived threat to worker health (combining "great" and "some" responses), whereas less than $40 \%$ perceived an impact on work productivity resulting from the dust, and less than $50 \%$ perceived an impact to customer satisfaction. Customer satisfaction received the largest score in both the "great impact" $(9.5 \%)$ and the "no impact" $(20.8 \%)$ categories. Fifteen percent of firm owners perceived no impact to productivity and $16 \%$ perceived no impact to worker health.

\section{Dust Control Technology Use}

Summary statistics for use of the dust control technologies are presented in Table II, and reporting percentages are depicted in Figure 2. Among the dust control technologies, respiratory protection was the most commonly used. The technology with the greatest response in the "always" category was respiratory protection $(80.3 \%$ ), a score that was substantially higher than that of any of the other technologies.

Combined responses for the "rarely" and "never" categories revealed that half the firm owners report very low usage rates for wet methods (50.8\%) and low-dust compound (45.1\%). Combined responses for the "always" and "often" ratings indicated that nearly all the firms use respiratory protection on a frequent basis (92\%), and a substantial number use pole sanders $(73.8 \%)$ and ventilated sanders $(40.1 \%)$. Less than $10 \%$ of firms reported using the wet methods on an "often" or "always" basis. 


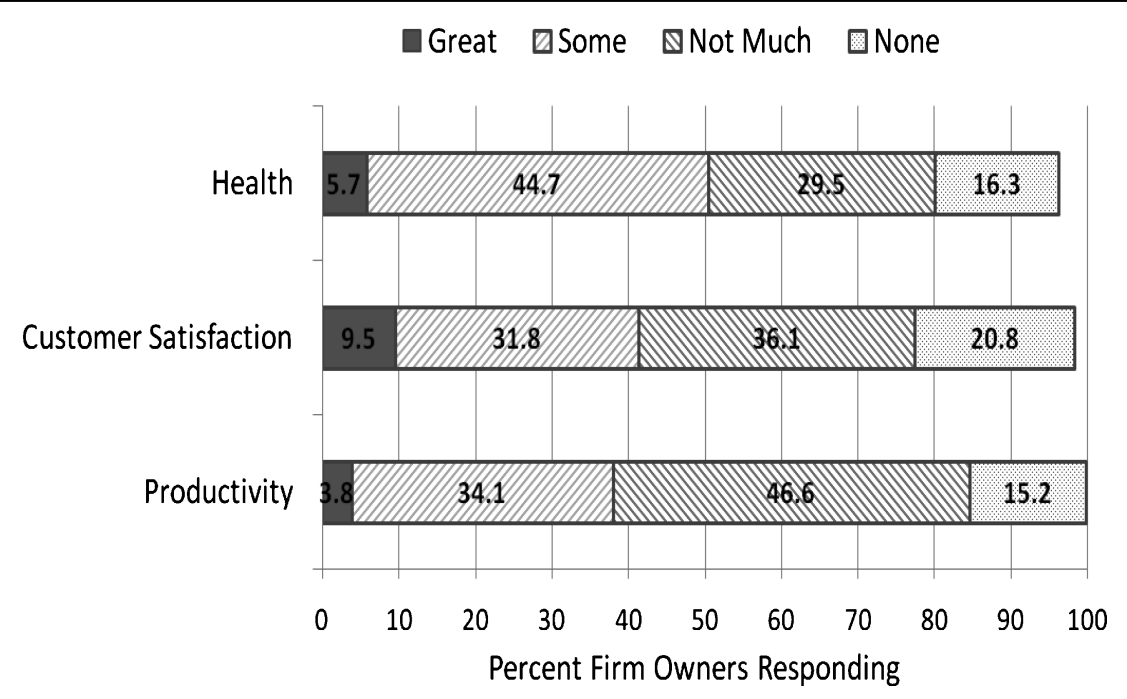

FIGURE 1. Firm owner perception of risk associated with drywall dust

\section{Effects of Firm Size}

No effect of firm size on tool use frequency was found $(p=0.78)$. Investigation of the effect of firm size on responses to the three risk perception questions revealed a significant effect of firm size on the perception of risk to worker health $(\mathrm{F}(3$, $260)=3.77, p=0.011)$. Subsequent pairwise comparison of the means indicated that owners of small firms rated the risk to worker health as greater than did the owners of other size-class firms $(\mathrm{p}=0.01)$.

\section{Content Analysis}

Perception of Risk

Analysis of the open-ended responses yielded $10 \mathrm{com}$ ments that pertained to worker health, 4 pertained to customer

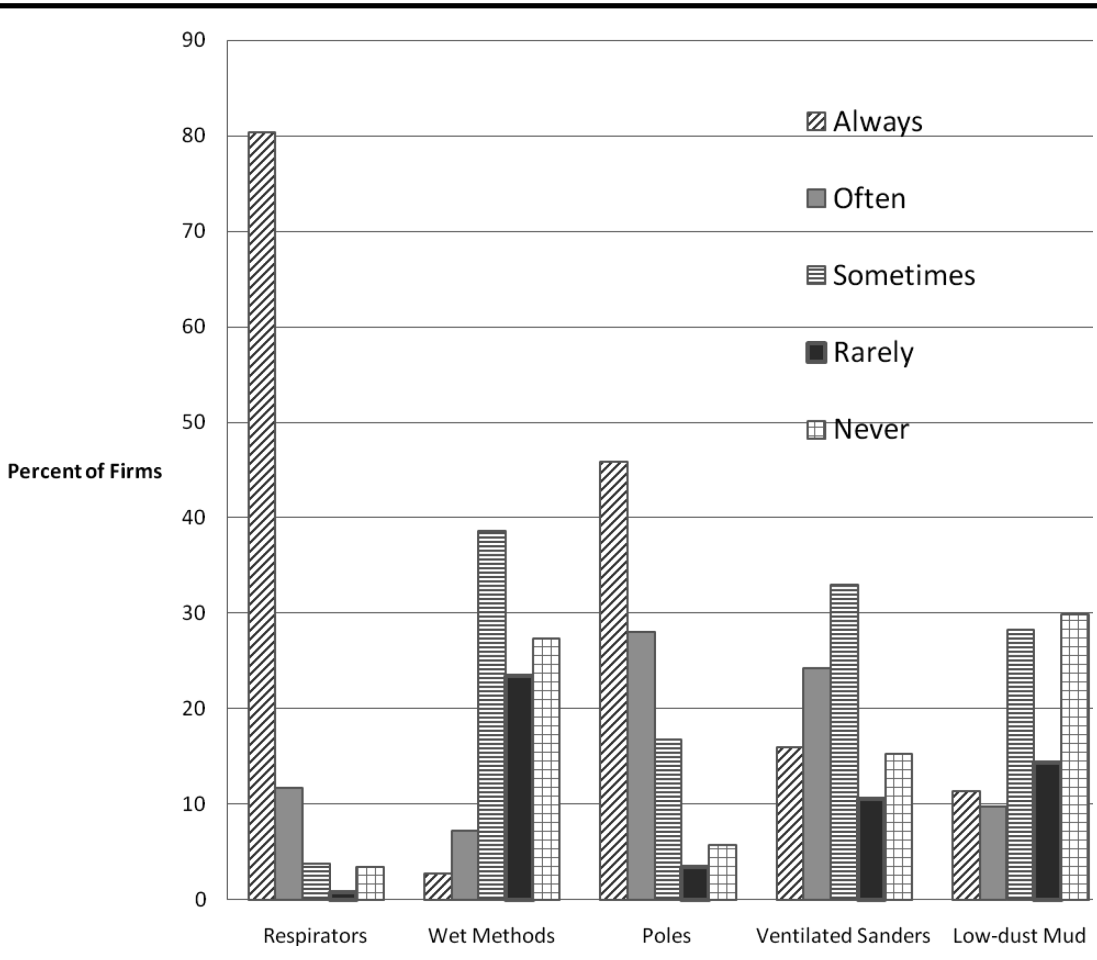

FIGURE 2. Firm usage of dust control technologies 
satisfaction, and 2 pertained to productivity. Of the 10 comments pertaining to health, 2 indicated that there is a risk to health, and 8 indicated a minimal perception of the risk to worker health. All comments pertaining to customer satisfaction (4) and productivity (2) indicated a perceived risk.

\section{Dust Control Technology Use}

Emergent themes were that quality and productivity are primary barriers associated with the wet methods. Barriers to the use of ventilated sanders are usability and environmental factors. Environmental factors included aspects of the work setting that served to make the use of the ventilated tool impractical, such as the size of the work space and access to electrical power. The use of low-dust joint compound is primarily impacted by product availability and its new status on the market. Emergent themes associated with the pole sander and ventilated sander were that firm owners were not considering their utility as worker protection tools. Many comments reflected that pole sanders were not considered useful in reducing worker exposure to dust. Comments pertaining to the ventilated sander indicated confusion between ventilated sanding tools and general room ventilation or shop vacuum tools.

TABLE III. Open-Ended Responses for Those Answering "Rarely" or "Never" Regarding Use of Low Dust Compounds-Why Not Used

\begin{tabular}{|c|c|c|}
\hline $\begin{array}{l}\text { Response } \\
\text { Code/Category }\end{array}$ & Frequency & Subcategories \\
\hline New & 43 & $\begin{array}{l}\text { So new to market that firm } \\
\text { hasn't tried yet } \\
\text { Too new to be found } \\
\text { effective } \\
\text { Have heard of it-thinking } \\
\text { of using it } \\
\text { Would rather stick with } \\
\text { familiar product } \\
\text { Not yet available in local } \\
\text { market } \\
\text { Trying it now }\end{array}$ \\
\hline Unfamiliar & 24 & Not aware of product \\
\hline Cost & 7 & $\begin{array}{l}\text { Costs more than regular } \\
\text { mud } \\
\text { No incentive to buy more } \\
\text { expensive product }\end{array}$ \\
\hline Quality & 9 & $\begin{array}{l}\text { Failure to achieve desired } \\
\text { surface } \\
\text { Doesn't seem to really } \\
\text { work at reducing dust } \\
\text { Doesn't sand as easily }\end{array}$ \\
\hline $\begin{array}{l}\text { Total responding } \\
\text { to item }\end{array}$ & 83 & \\
\hline
\end{tabular}

TABLE IV. Open-Ended Responses for Those Answering "Rarely" or "Never" Regarding Use of Wet Methods-Why Not Used

\begin{tabular}{lcc}
\hline $\begin{array}{l}\text { Response } \\
\text { Code/Category }\end{array}$ & Frequency & Subcategories \\
\hline Quality & 20 & $\begin{array}{c}\text { Hard to achieve desired } \\
\text { texture/result } \\
\text { Puts moisture back into } \\
\text { board } \\
\text { Takes too much time } \\
\text { Not cost effective } \\
\text { Productivity }\end{array}$ \\
& 25 & $\begin{array}{c}\text { Easier/faster to sand dry } \\
\text { compound vs. wet } \\
\text { Creates mess from } \\
\text { dripping }\end{array}$ \\
Mess & 7 & $\begin{array}{c}\text { Creates mess on tools } \\
\text { needing to be rinsed }\end{array}$ \\
& & \\
Total responding & 52 & \\
\hline
\end{tabular}

There were very few comments associated with respiratory protection, since most firms use that technology on a frequent basis. Analysis of responses to the open-ended questions soliciting information from those firm owners answering "rarely" or "never" on a question about dust control technology use are summarized in Tables III-V.

\section{DISCUSSION}

$\mathrm{T}$ he present work is part of a larger effort to identify barriers inherent to the drywall finishing work system that are preventing the use of available dust control technologies. In this larger project, three sociotechnical subsystems (organizational, personnel, and technological) of the work system were evaluated to identify key causal factors. In the present study, the organizational subsystem was evaluated through interviews of firm owners to identify management perspectives on the available technologies and also on the risks associated with the drywall dust, with the intent of identifying barriers to technology adoption.

\section{Firm Owner Perceptions of Risk}

Less than half the firm owner respondents perceived that drywall dust presents a serious threat to customer service or productivity, and roughly half perceived a risk to worker health. These results suggest that owners are not accurately assessing the objective risk to workers imposed by dust exposure. Drywall joint compound has been found to contain crystalline quartz (silica), talc, and mica, and a previous case study found that worker exposures exceeded occupational 
TABLE V. Open-Ended Responses for Those Answering "Rarely" or "Never" Regarding Use of Ventilated or Vacuum Sanders-Why Not Used

\begin{tabular}{|c|c|c|}
\hline $\begin{array}{l}\text { Response } \\
\text { Code/Category }\end{array}$ & Frequency & Subcategories \\
\hline Occupants & 21 & $\begin{array}{l}\text { Perceived usefulness in } \\
\text { protecting building } \\
\text { occupants or } \\
\text { equipment, rather } \\
\text { than for workers. } \\
\text { Comments such as } \\
\text { new construction } \\
\text { only, no occupied } \\
\text { spaces. Comments } \\
\text { also about usefulness } \\
\text { in particular building } \\
\text { types: hospitals, } \\
\text { schools, electronic } \\
\text { equipment spaces }\end{array}$ \\
\hline Use & 9 & $\begin{array}{l}\text { Comments about } \\
\text { problems associated } \\
\text { with use. } \\
\text { Not able to achieve } \\
\text { desired surface } \\
\text { Workers not able to } \\
\text { learn to use } \\
\text { Clogs and vacuum } \\
\text { emptying }\end{array}$ \\
\hline Environmental Factors & 2 & $\begin{array}{l}\text { No electricity on new } \\
\text { construction } \\
\text { Hard to use in small } \\
\text { spaces } \\
\text { Hard to use in large } \\
\text { spaces - cord } \\
\text { limitations }\end{array}$ \\
\hline Productivity & 13 & $\begin{array}{l}\text { Takes longer to do job } \\
\text { Cost } \\
\text { Loss due to theft }\end{array}$ \\
\hline $\begin{array}{l}\text { Total responding } \\
\text { to item }\end{array}$ & 45 & \\
\hline
\end{tabular}

exposure limits. ${ }^{(7)}$ In this investigation, NIOSH found that 8 of 9 total dust samples exceeded the OSHA PEL and 2 of 13 exceeded the respirable PEL. Respirable silica (quartz) was detected in 17 of the 22 samples analyzed. Silica, talc, and mica are regulated by OSHA in its standards for the construction industry. ${ }^{(16)}$ Considerable educational material regarding the health effects associated with silica has been published by OSHA and NIOSH and targeted to the construction industry audience. In light of this, the firm owner risk perception to worker health is lower than what would be expected.
Analysis of the firm owner responses to the open-ended questions did reveal that there is an understanding among some in the industry that drywall dust contains silica. Several comments indicated an understanding of the health risks associated with the dust and that silica is a known constituent of the compound. Some respondents expressed a desire to reduce the dust and a need for improved methods of control. However, there were more responses indicating a tacit acceptance of the risk as being inherent to the work and, thus, unavoidable. Overall, these findings indicate a need to address firm owner perceptions of the risk to worker health associated with drywall dust exposure.

\section{Technology Usage Rates}

Respiratory protection is notably the most commonly used method of controlling worker exposure to drywall dust. The results for the frequency of use of pole sanders were also high, but most respondents indicated that the poles are used for reaching overhead areas, not for the expressed purpose of controlling dust. Many firm owners questioned the effectiveness of the pole sander as a means of protecting workers. NIOSH has recommended the use of pole sanders for this purpose. ${ }^{(11)}$ A recent study ${ }^{(12)}$ found them to significantly reduce thoracic and respirable dust concentrations in the worker breathing zone, over those dust concentrations generated from basic block sanders. The ventilated vacuum sanders and low-dust joint compound are used by $40 \%$ and $20 \%$, respectively, of the firms that responded.

Responses to open-ended questions, however, revealed that some respondents were referring to shop vacuums for postwork cleanup or whole-room ventilation in their affirmative answers. Wet methods were the least preferred, with only $10 \%$ reporting use, although this is the method suggested by the AWCI in its published guide for finishing gypsum board. These results indicate an over-reliance on the least preferred class of hazard control: personal protective equipment. This suggests a contemporary need to increase the use of more effective controls, such as the ventilated sander or low-dust joint compound, which do not place the onus of hazard control on the worker.

Content analysis of the comments revealed that many firm owners misunderstand the difference between ambient dust control and dust control to protect workers from exposure. Many comments were made about general dilution ventilation and dust containment systems. Such systems serve to reduce ambient dust levels rather than worker breathing zone concentrations. Several comments indicated that firms take dust control precautions in particular construction settings, such as public schools, hospitals, or buildings containing sensitive electronic equipment. Responses to open-ended questions indicated a belief that new construction situations, with open windows and walls or with room fans, would not present an exposure risk.

When asked about additional methods of controlling dust, respondents mentioned the use of barriers and containment systems, which are designed to prevent dust migration from 
the work area into other building spaces but have no value in protecting workers from overexposure. The emphasis of these comments was placed on protecting building occupants and equipment from dust exposure rather than protecting workers.

These findings indicate a need for educational interventions to increase knowledge of appropriate controls and awareness of the need for effective worker protection controls. Open-ended responses also indicated that workers were provided respiratory protective equipment but that its use was not consistent. There was a prevailing theme that owners considered it the responsibility of the worker to choose to wear the respiratory protection. The firm owners did not seem to recognize their own role in the establishment of policies and protocols to improve safety and health of the work force.

\section{Barriers to Adoption of Dust Control Technology}

Analysis of the open-ended comments revealed important potential barriers to the adoption of dust control technologies (Table IV). For the ventilated sanders, which were highly effective at reducing worker exposure to dust, ${ }^{(12)}$ the firm owners identified issues associated with usability, productivity, and the work environment. Usability concerns identified were that the workers would take longer to learn to use the technology and that it would be more difficult to attain the desired surface texture. Also noted were problems associated with the size of the technology and how that would limit maneuverability in small spaces.

Further, the power cord was a noted limitation to use of the device for sanding large areas, since it would limit worker movement. Productivity issues identified were that the workers currently have a level of proficiency with the block sanders and that the more complicated ventilated sanders would require time for learning and skill development. In addition, the need to empty dust collection containers and lines was perceived as a hindrance to productivity. Considered a barrier in several comments was the cost for initial purchases and to replace equipment from theft. A key work environmental factor was mentioned by several respondents: technology requires a power source that is not always available in locations close enough to the work.

Primary barriers to the use of the low-dust joint compound were that the product is not available in all markets and it is unfamiliar to firm owners (Table V). Firm owners expressed a need for more information about the product, ease of sanding, and surface quality before committing to switch to its use. The cost of the product was also an issue for the respondents. There were frequent mentions of a lack of incentive to switch to a product that would be more costly.

Pole sanders are currently in use in the industry but not for the purpose of protecting workers. Respondents questioned their effectiveness as dust control measures stating that workers are "still covered in dust" after their use. Comments pertaining to wet methods illustrated a pervasive dissatisfaction with this technology (Table IV). Most comments pertained to quality of finished surface, productivity, and mess created by the method. The productivity issues centered on the need for frequent rewetting and rinsing of sponges. Respondents overwhelmingly communicated that this method is infeasible for large-scale finishing work.

\section{Limitations and Future Direction}

Several limitations were inherent in the present study. Since this study relies on self-report on a topic with some legal and regulatory risk, there is a possibility of response bias in the data. To control for this, the survey protocol began with an explanation of the study objective and an assurance that only aggregate data would be published. A second limitation stems from the fact that the census population was limited to firms that had membership in large trade organizations, with an associated potential for reduced external validity. Firms that opt to join trade organizations tend to be larger than those without membership. For this reason, the present study included analyses to test for the effects of firm size on findings. Since there was a significant effect of firm size, future research is needed into the trends associated with smaller firms without trade organization affiliation.

Finally, there has been considerable discussion in the risk perception literature regarding the reliance on scaled questionnaire instruments for the assessment of risk perception. ${ }^{(17)}$ The principal arguments have been that a scaled response provides an overly simplistic measure of a highly complex cognitive process. While the present study did employ qualitative measures, in addition to the scaled items, it is understood that the metrics might still lack a degree of depth.

\section{CONCLUSIONS}

he goal of this research was to provide input into the design of an effective intervention strategy to improve worker protection from drywall finishing dust. Of particular importance are the root causes of current low adoption rates of the most effective dust control technologies; those barriers will be key in intervention design. ${ }^{(18)}$ The primary barriers to the use of the ventilated sanders were concerns over tool usability and productivity. Firm owners expressed concern that workers would not be able to produce quality work with the efficiency necessary, with the more complicated tool.

Additional barriers pertained to the work environment. A frequently cited example of such a barrier is the limited access to a power source on many new construction sites. Also, the tool's size could prevent its use in either very small or very large spaces due to its length and the limitations of the power cord, respectively. The primary barriers to the use of the lowdust joint compound are the lack of availability and cost issues. Firm owners noted a lack of incentive to switch to a higher cost product.

Pole sanders are currently in common use in the industry. They are not used for the specific purpose of worker protection; however, that would be an indirect outcome. Wet methods, while offering some degree of protection, rated very poorly in this study and in other recent studies of worker perceptions and 
tool usability. ${ }^{(12)}$ Therefore, this method is not recommended by the authors as the targeted preferred control method. Ventilated sanders and material substitution with lower-dust-yield joint compound are more promising solutions to this occupational health problem. To improve industry usage rates of these products, primary recommendations are: (1) the redesign of the ventilated sanders to address concerns and increase adjustability, and (2) and improved market access to the lowdust joint compound.

\section{ACKNOWLEDGMENTS}

$\mathrm{T}$ his research was made possible through grant funding received from The Center for Innovation in Construction Safety and Health at Virginia Tech, which has received research grant funding from the National Institute for Occupational Safety and Health.

\section{REFERENCES}

1. Wang, E., J.M. Dement, and H. Lipscomb: Mortality among North Carolina construction workers, 1988-1994. Appl. Occup. Environ. Hyg. 14:45-58 (1999).

2. Stern, F., E. Lehman, and A. Ruder: Mortality among unionized construction plasterers and cement masons. Am. J. Ind. Med. 39(4):373388 (2001).

3. Sauni, R., P. Oksa, S. Huikko, P. Roto, and J. Uitti: Increased risk of asthma among Finnish construction workers. Occup. Med. (Lond) 53(8):527-531 (2003).

4. Arif, A.A., G.L. Delcos, L.W. Whitehead, S.R. Tortolero, and E.S. Lee: Occupational exposures associated with work-related asthma and work-related wheezing among U.S. workers. Am. J. Ind. Med. 44(4):36876 (2003).

5. Kaukiainen, A., R. Riala, R. Martikainen, K. Reijula, H. Riihimaki, and L. Tammilehto: Respiratory symptoms and diseases among construction painters. Int. Arch. Occup. Environ. Health 78(6):452-458 (2005).
6. Sauni, R., P. Oksa, K. Vattulainen, J. Uitti, P. Palmroos, P. Roto: The effects of asthma on the quality of life and employment of construction workers. Occup. Med. (Lond) 51(3):163-167 (2001).

7. National Institute for Occupational Safety and Health (NIOSH): Health Hazard Evaluation Report 94-0078-2660 by A.K. Miller, E.J. Esswein, and J. Allen. Cincinnati, Ohio: NIOSH, 1997.

8. Verma, D.K., L.A. Kurtz, D. Sahai, M.M. Finkelstein: Current chemical exposures among Ontario construction workers. Appl. Occup. Environ. Hyg. 18:1031-1047 (2003).

9. Rappaport, S.M., M. Goldberg, P. Susi, and R.F. Herrick: Excessive exposure to silica in the U.S. construction industry. Ann. Occup. Hyg. 47(2):111-122 (2003).

10. Bohadana, A.B., N. Massin, P. Wild, and G. Berthiot: Airflow obstruction in chalkpowder and sugar workers. Int. Arch. Occup. Environ. Health 68(4):243-248 (1996).

11. Mead, K.R., and A.K. Miller: National Institute for Occupational Safety and Health (NIOSH) Health Hazard Evaluation: Control of Drywall Dust. Appl. Occup. Environ. Hyg. 15:820-821 (2000).

12. Young-Corbett, D.E.: "Evaluation of Dust Control Technologies for Drywall Finishing Operations: Industry Implementation Trends, Worker Perceptions, Effectiveness and Usability." Unpublished PhD dissertation, Virginia Tech, Blacksburg, Va., 2007. Available at http://scholar.lib.vt.edu/theses/available/etd-08102007-094314/.

13. "National Construction Agenda." [Online] Available at http://www.cdc. gov/niosh/nora/comment/agendas/construction/pdfs/ConstOct2008.pdf (Accessed November 1, 2008)

14. United States Census Bureau: Statistics of U.S. Businesses; Drywall and Insulation Contractors. NAICS 23831, 2004: Washington, DC: Bureau of the Census.

15. Krippendorff, K.: Content Analysis: A Guide to Its Methodology, 2nd ed. New York: Sage Publications, 2005.

16. "Safety and Health Regulations for Construction," Code of Federal Regulations, Title 29 Part 1926.55, 2006. pp. 30-43.

17. Aven, T., and V. Kristensen: Perspectives on risk: Review and discussion of the basis for establishing a unified and holistic approach. Reliability Engineer. Sys. Safety. 90(1):1-14 (2005).

18. Young-Corbett, D.E., and B.M. Kleiner: Drywall finishing industry: Macro-ergonomic evaluation and intervention design. In Human Factors in Organizational Design and Management - IX, L. Sznelwar, F. Marcia and U. Montedo (eds.). Proceedings of the 9th International Symposium on Human Factors in Organizational Design and Management, Sao Paulo, Brazil, March 19-21, 2008 